\title{
New Disease Reports \\ Neofusicoccum parvum, agent of leaf spot on the new host Ginkgo biloba in Iran
}

\author{
H.A. Mirhosseini, V. Babaeizad and S. Rahimlou*
}

Department of Plant Protection, Sari Agricultural Sciences and Natural Resources University, PO Box 578, Mazandaran, Sari, Iran

*E-mail: S.Rahimlou261989@gmail.com

Received: 02 Jun 2014. Published: 13 Sep 2014. Keywords: $\beta$-tubulin, ITS-rDNA

Ginkgo (Ginkgo biloba) is increasingly popular as a street, park and specimen tree in Iran. Historically, it is very ancient having fossils recognisably related to modern ginkgo from the Permian Period, dating back 270 million years ago. In September and October 2013, a moderately severe leaf spot was observed on ginkgo cultivated in some parks and green spaces in Sari, Iran (Mazandaran province). Considerable defoliation was noted with approximately $50 \%$ of the trees showing symptoms. Spots originate as water-soaked patches and then develop into irregular areas that finally are ashen in the centre with a dark reddish brown border (Fig. 1). Such spots may occur in any location on the leaf and are not limited to the radiating vascular bundles.

A fungus with grey-black colonies was consistently isolated from the leaf spots on potato dextrose agar (PDA), but produced few conidia. Abundant pycnidia and conidia developed when isolates were cultured on $2 \%$ water agar at $25^{\circ} \mathrm{C}$ under near-UV light for two weeks. Conidia were hyaline, ellipsoid, unicellular, with a sub-truncate base, 20-28 (24.4) x 4-6.5 (5.2) $(\mathrm{n}=50)$. The pathogen was identified as Neofusicoccum parvum on the basis of morphology (Crous et al., 2006). A representative isolate was characterised by sequencing of the internal transcribed spacer (ITS) rDNA using ITS4/ITS5 primers (White et al., 1990) and sequencing the $\beta$-tubulin gene (TUB2) using T1/T2 primers (O'Donnell \& Cigelnik, 1997). BLAST searches of GenBank showed close identity $(99-100 \%)$ of the isolate sequence to reference sequences for $N$. parvum (KC507808.1 and KC507806.1 for $\beta$-tubulin and KJ190288.1, KJ190287.1, KJ190286.1 for ITS). Amplified sequences from selected isolates were deposited in GenBank with the following accession numbers: KJ872493 (ITS) and KJ841779 (TUB)

Pathogenicity tests were done by inoculating each of 10 leaves on three seven-year-old trees with a mycelial plug $(0.5 \mathrm{~cm}$ diameter $)$ harvested from the periphery of a seven-day-old colony grown on PDA. An equal number of leaves on the same tree were inoculated with plugs of PDA medium to serve as controls. Inoculated leaves were covered with plastic bags for 24 hours after inoculation to maintain high relative humidity. The plugs were removed after 48 hours. After seven days, all of the inoculated leaves showed symptoms identical to those observed in the field under natural conditions, whereas controls remained symptom-free. Re-isolation of the fungus from lesions on inoculated leaves confirmed that the causal agent was $N$. parvum. A literature review for fungal diseases of G. biloba in Iran revealed only Phyllosticta ginkgo causing a leaf spot (Viennot-Bourgin et al., 1970), but no reports of $N$. parvum. However, $N$. parvum has been associated with grapevine decline in Iran (Mohammadi et al., 2013). To the best of our knowledge, this is first record of this pathogen as causal agent of leaf spot on ginkgo in the world.

\section{References}

Crous PW, Slippers B, Wingfield MJ, Rheeder J, Marasas WFO, Phillips AJL, Alves A, Burgess TI, Barber P, Groenewald JZ, 2006. Phylogenetic lineages in the Botryosphaeriaceae. Studies in Mycology 55, 235-253. http://dx.doi.org/10.3114/sim.55.1.235

Mohammadi H, Gramaje D, Banihashemi Z, Armengol J, 2013.

Characterization of Diploidia seriata and Neofusicoccum parvum associated with grapevine decline in Iran. Journal of Agricultural Science and Technology 15, 603-616.

O’Donnell K, Cigelnik E, 1997. Two divergent intragenomic rDNA ITS2 types within a monophyletic lineage of the fungus Fusarium are nonorthologous. Molecular Phylogenetics and Evolution 7, 103-116. http://dx.doi.org/10.1006/mpev.1996.0376

Viennot-Bourgin G, Ale-Agha N, Ershad D, Giffaut O, 1970. Les champignons parasites de l'Iran (Nouvelle contribution). Annales de Phytopathologie 2, 689-734.

White TJ, Bruns T, Lee S, Taylor J, 1990. Amplification and direct sequencing of fungal ribosomal genes for phylogenetics. In: Innis MA, Gelfand DH, Shinsky J, White TJ, eds. PCR protocols. A guide to methods and applications. San Diego, CA, USA: Academic Press, 315-322.

To cite this report: Mirhosseini HA, Babaeizad V, Rahimlou S, 2014. Neofusicoccum parvum, agent of leaf spot on the new host Ginkgo biloba in Iran. New Disease Reports 30, 12. http://dx.doi.org/10.5197/j.2044-0588.2014.030.012 